\title{
Sensor-based demand-controlled ventilation: a review
}

\author{
William J. Fisk ${ }^{a}$, Anibal T. De Almeida ${ }^{b, *}$ \\ andoor Environment Department, Lawrence Berkeley National Laboratory, Berkeley, CA, USA \\ ${ }^{b}$ Dep. Eng. Electrotecnica, Universidade de Coimbra, Polo II, 3030 Coimbra, Portugal
}

Received 26 September 1997; accepted 16 April 1998

\begin{abstract}
With sensor-based demand-controlled ventilation (SBDCV), the rate of ventilation is modulated over time based on the signals from indoor air pollutant or occupancy sensors. SBDCV offers two potential advantages: better control of indoor pollutant concentrations, and lower energy use and peak energy demand. Based on theoretical considerations and on a review of literature, SBDCV has the highest potential to be cost-effective in applications with the following characteristics: (a) a single or small number of pollutants dominate so that ventilation sufficient to control the concentration of the dominant pollutants provides effective control of all other pollutants; (b) large buildings or rooms with unpredictable temporally variable occupancy or pollutant emission; and (c) climates with high heating or cooling loads or locations with expensive energy. At present, most SBDCV systems are based on monitoring and control of carbon dioxide $\left(\mathrm{CO}_{2}\right)$ concentrations. There is a limited number of well-documented case studies that quantify the energy savings and the cost-effectiveness of SBDCV. The case studies reviewed suggest that in appropriate applications, SBDCV produces significant energy savings with a payback period typically of a few years. (C) 1998 Elsevier Science S.A. All rights reserved.
\end{abstract}

Keywords: Demand-controlled; Energy; Indoor air quality; Sensors; Ventilation

\section{Introduction}

The quality of the indoor environment depends upon a number of factors including the concentrations of a varicty of gaseous and particulate pollutants in the indoor air. These air pollutants may enter the building with outside air or may be generated internally. For indoor-generated pollutants, indoor concentrations often substantially exceed the background outdoor concentrations.

One class of indoor air pollutants of importance to sensorbased demand-controlled ventilation (SBDCV) are the bioeffluents emitted by occupants which influence the acceptability of the air. Carbon dioxide $\left(\mathrm{CO}_{2}\right)$ is one of the bioeffluents. Humans are normally the main indoor source of $\mathrm{CO}_{2}$, leading to an increase of indoor concentrations relative to the outdoor levels. The outdoor $\mathrm{CO}_{2}$ concentration is approximately $350 \mathrm{ppm}$ and indoor concentrations are usually in the range of 500-2000 ppm. At these concentrations, $\mathrm{CO}_{2}$ is not thought to be a direct cause of adverse health effects; however, $\mathrm{CO}_{2}$ is an easily measured surrogate for other occupantgenerated pollutants, such as body odors. The indoor $\mathrm{CO}_{2}$ concentration is often used as an indicator of the rate of

\footnotetext{
* Corresponding author. Tel.: + 35139 796218; fax: + 35139 406672;
} e-mail: aalmeida@isr.uc.pt outside air supply per occupant, although it is an imperfect indicator [1]. The minimum ventilation rates in the current version of ASHRAE Standard 62 'Ventilation for Acceptable Indoor Air Quality' are selected, in part, to maintain indoor $\mathrm{CO}_{2}$ concentrations below $1000 \mathrm{ppm}$ [2].

Water vapor is generated indoors due to human metabolism and human activities as well as from unvented combustion. The generally accepted range in relative humidity for human comfort is approximately in $25-60 \%$ [3]. The implications of high humidity for human health and for the growth of indoor microorganisms are complex and controversial $[4,5]$.

The indoor air typically contains dozens of volatile organic compounds (VOCs) at measurable concentrations. VOCs are emitted indoors by building materials, furnishings, equipment, cleaning products, combustion activities, human metabolism, and perfumes. The outdoor air also contains VOCs that enter buildings. Some VOCs are suspected or known carcinogens. Some VOCs have unpleasant odors or are irritants. The total volatile organic compound (TVOC) concentration, often used as a simple, integrated measure of the VOCs, is the total mass of measured VOCs per unit volume of air, exclusive of very volatile (e.g., furmaldehyde) organic compounds. Laboratory studies in which humans have been exposed to mixtures of VOCs under controlled 
conditions [6,7] have documented increased health symptoms at TVOC concentrations of the order of milligrams per cubic meter of air. As an indicator of health effects, the TVOC concentration is inherently flawed because the potency of individual VOCs to elicit irritancy symptoms varies by orders of magnitude [8]. The potency for other potential health effects such as cancer is also highly variable among compounds. Despite these limitations, unusually high TVOC concentrations, above 1 or $2 \mathrm{mg} \mathrm{m}^{-3}$, may provide an indication that adverse health effects from TVOCs are likely.

Particles are present in outdoor air and are also generated indoors from a large number of sources including tobacco smoking and other indoor combustion processes. Some particles may be generated by indoor equipment (e.g., copy machines and printers). Mechanical abrasion and air motion may cause particle or fiber release from indoor materials. Particles are also produced by people. For example, skin flakes are shed and droplet nuclei are generated from sneezing and coughing. Particles may contain toxic chemicals. Some particles, biologic in origin, may cause allergic reactions or be a source of infectious disease. Of particular concern are the particles smaller than approximately $2.5 \mu \mathrm{m}$ in diameter, which are more likely to deposit deep inside the lungs [9].

At equilibrium, indoor pollutant concentrations depend on the outdoor concentration, on indoor pollutant source strengths and on the total rate of pollutant removal. For many indoor-generated air pollutants, ventilation with outside air is usually the dominant pollutant removal process. Local exhaust ventilation is often used near concentrated pollutant sources to minimize the transport of pollutants from these sources to surrounding indoor areas. General ventilation, i.e., ventilation that occurs throughout the building or zone, improves the indoor environment by diluting and removing the indoor-generated pollutants with outside air. Although general ventilation is often the dominant process of indoor pollutant removal, pollutant source control and local ventilation are usually more energy efficient and effective options for controlling indoor air quality and should be used to reduce the required quantity of general ventilation. General ventilation is still required in virtually all buildings because buildings contain some spatially-distributed indoor pollutant sources that cannot be eliminated. The technique of SBDCV is usually applied to general ventilation (hercinafter general ventilation is called ventilation).

\section{Influence of ventilation rate on indoor pollutant concentrations}

To properly apply SBDCV, it is necessary to have a general understanding of equilibrium relationships between ventilation rate and indoor air pollutant concentrations and also an understanding of the nature of the temporal response of indoor pollutant concentration to a change in ventilation rate. To illustrate these relationships, we start with a transient model for a pollutant in a building or zone with thoroughly mixed indoor air, a stable indoor pollutant emission rate that is independent of the indoor pollutant concentration, and a constant rate of ventilation. Many previous papers have presented such models (e.g., Refs. $[1,10,111)$. The rate of pollutant removal by radioactive decay or chemical reaction within the indoor air is assumed to be negligible. The mass balance equation is

$\frac{\mathrm{d} C}{\mathrm{~d} t}=\frac{G}{V}+\lambda_{\mathrm{v}} C_{\text {out }}-\lambda_{\mathrm{v}} C-v_{\mathrm{d}} \frac{S}{V} C-\frac{Q_{\mathrm{ac}}}{V} C \varepsilon_{\mathrm{ac}}$

where $C$ is the indoor concentration, $t$ is the time variable, $G$ is the indoor pollutant generation rate, $V$ is the indoor air volume, $\lambda_{v}$ is the air exchange rate (outside air flow divided by indoor air volume), $C_{\text {out }}$ is the outdoor concentration, $v_{\mathrm{d}}$ is the deposition velocity for the pollutant, $S$ is the area of surfaces on which indoor pollutants are removed by deposition, $Q_{\mathrm{ac}}$ is the rate of air flow through an air cleaner, and $\varepsilon_{\mathrm{ac}}$ is the efficiency of the air cleaner. The deposition velocity, $v_{\mathrm{d}}$, may be a function of several building characteristics such as indoor air velocities, the nature of indoor surfaces, and the prior exposures of surfaces to pollutants [10]. For simplicity, we have used a form of the equation that is appropriate for situations when only recirculated indoor air (not a mixture of outside and recirculated air) passes through the air cleaner. This paper provides only a few examples of modeled relationships between ventilation rate and indoor pollutant concentration. Additional examples are provided in the report on which this paper is based [12].

At equilibrium, if the ventilation rate is expressed as a flow rate per person ( $\left.Q_{\text {person }}\right)$, the pollutant emission rate is a per person value $\left(G_{\text {person }}\right), v_{\mathrm{d}}$ is negligible, and there is no air cleaning, Eq. (1) reduces to

$c=C_{\text {out }}+\frac{G_{\text {person }}}{Q_{\text {person }}}$

Fig. 1 presents an example of the application of Eq. (2) for predicting equilibrium indoor carbon dioxide concentrations in an office setting. The relationship depicted in Fig. 1 is often used to establish the $\mathrm{CO}_{2}$ concentration setpoint in SBDCV systems; however, this relationship must be used with caution

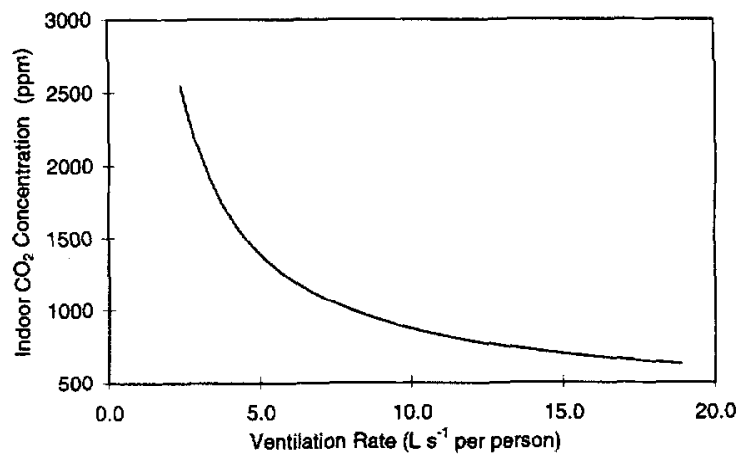

Fig. 1. Equilibrium relationship between indoor carbon dioxide concentration and ventilation rate on Eq. (2). A carbon dioxide generation rate of $0.301 \mathrm{~min}^{-1}$ per person and an outdoor concentration of $350 \mathrm{ppm}$ were assumed. 


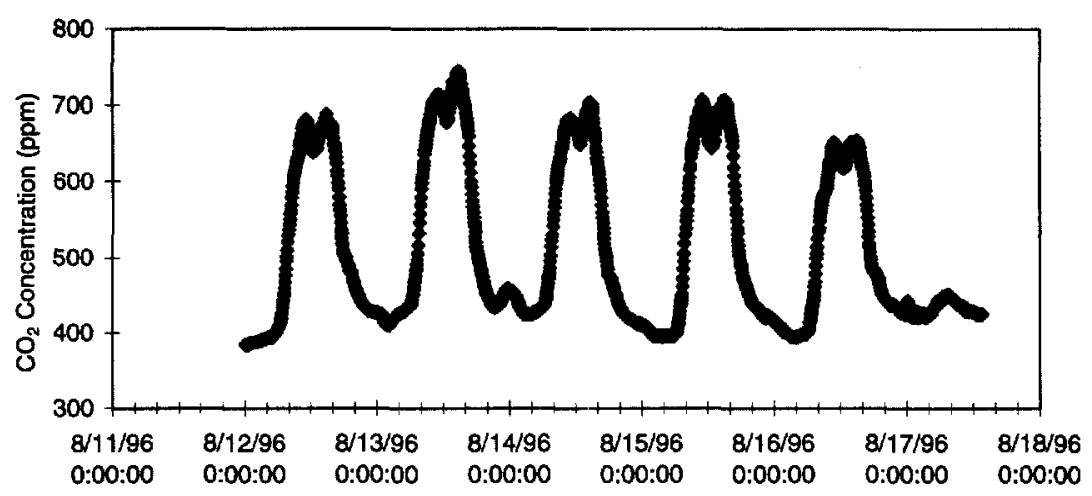

Fig. 2. Example time history of $\mathrm{CO}_{2}$ concentration inside an office building.

because carbon dioxide concentrations often do not reach equilibrium in office buildings. For example, Fig. 2 shows an example of the actual measured time history of indoor $\mathrm{CO}_{2}$ concentration in an office building. Through inspection of the figure, it is evident that $\mathrm{CO}_{2}$ concentrations never stabilized at an equilibrium value. Thus, measured peak $\mathrm{CO}_{2}$ concentrations often cannot be used to determine rates of outside air supply per occupant.

SBDCV systems must respond to changes in indoor pollutant generation through appropriate adjustment of ventilation rates. When pollutant source strengths change or ventilation rates are increased or decreased, indoor pollutant concentrations will decrease or increase over time until a new equilibrium concentration is attained. The nature of the response can be derived from the transient version of the mass-balance equation. For simplicity, we consider only situations with no pollutant deposition or air cleaning, with perfect mixing of the indoor air, and with a constant pollutant source strength. For these conditions, the solution to Eq. (1) is

$C=C_{\text {equil }}+\left(C(0)-C_{\text {equil }}\right) \mathrm{e}^{-\lambda_{\mathrm{y}} t}$

with initial condition $C(0)$ and equilibrium concentration

$C_{\text {equil }}=C_{\text {out }}+\frac{G / V}{\lambda_{\mathrm{v}}}$

If

$C^{\prime}=C-C_{\text {out }}$

Eq. (3) becomes

$C^{\prime}=C_{\text {equil }}{ }^{\prime}+\left(C^{\prime}(0)-C_{\text {equil }}{ }^{\prime}\right) \mathrm{e}^{-\lambda_{v} t}$

If the indoor and outdoor concentration are identical $\left(C^{\prime}(0)=0\right)$ at time equals 0 and a pollutant source is introduced in the building

$\frac{C^{\prime}}{C_{\text {equil }}^{\prime}}=1-\mathrm{e}^{-\lambda_{r} t}$

Eq. (7) indicates that the time to attain an equilibrium concentration after the introduction of (or step change in) a pollutant source (e.g., people) in a building depends on the air exchange rate of the building. The reciprocal of the air exchange rate is called the nominal time constant. If the air change rate is $1 \mathrm{~h}^{-1}$, a typical minimum value for an office building, the nominal time constant for the ventilation process equals $1 \mathrm{~h}$. During one nominal time constant after the introduction of a pollutant source inside the building, the pollutant concentration difference (indoor concentration minus outdoor concentration) will increase to $63 \%$ of the equilibrium pollutant concentration difference. After two and three time constants, the indoor pollutant concentration difference will increase to $86 \%$ and $95 \%$, respectively, of the equilibrium value. The response of indoor pollutant concentration to a step change in air exchange rate, with a constant indoor pollutant source, is indicated by Eq. (6). In Fig. 3, the predicted concentration time history is illustrated for air exchange rates of $2 \mathrm{~h}^{-1}$ and $3 \mathrm{~h}^{-1}$, assuming the outdoor pollutant concentration is negligible, the initial air exchange rate is $1 \mathrm{~h}^{-1}, G /$ $V$ equals unity, and the initial indoor concentration before the step change is at the equilibrium value for the ventilation rate of $1 \mathrm{~h}^{-1}$.

\section{Basics of SBDCV}

In most buildings, occupancy and indoor pollutant emission rates vary with time but minimum ventilation rates are constant (except for unintentional changes in minimum ventilation with time). With SBDCV, the rate of ventilation is automatically varied to compensate for the changes in pollutant generation or occupancy. Pollutant or occupancy sen-

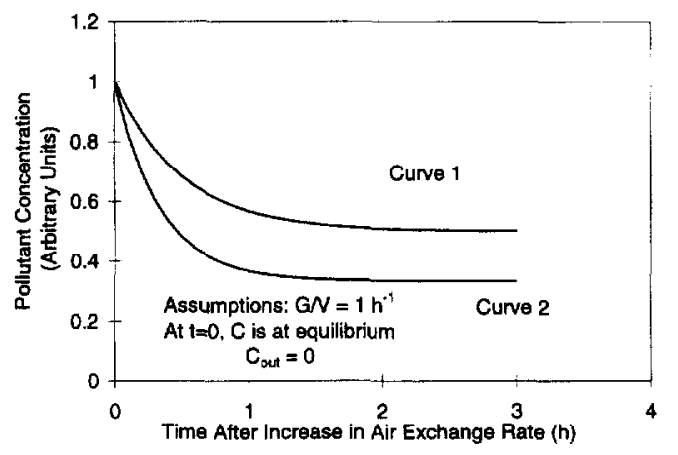

Fig. 3. Predicted time history of pollutant concentration after ventilation rate is from $1 \mathrm{~h}^{-1}$ to $2 \mathrm{~h}^{-1}$ (curve 1) or $1 \mathrm{~h}^{-1}$ to $3 \mathrm{~h}^{-1}$ (curve 2). 
sors are used to determine the need for outside air. SBDCV has the potential to improve indoor air quality by increasing the rate of ventilation when indoor pollutant generation rates are high and occupants are present. SBDCV can also save energy by decreasing the rate of ventilation when indoor pollutant generation rates are low or occupants are absent.

SBDCV is only applicable when certain conditions apply. There must be a basis for selecting a maximum acceptable pollutant concentration. A suitable pollutant sensor with a real time (or near real-time) output signal is required. A means of automatically adjusting the outside air supply is required. SBDCV is likely to be much more cost effective when the following additional conditions apply: (a) the building has one or a few dominant pollutants; (b) the indoor pollutant emission rate of the dominant pollutant varies considerably over time; (c) the indoor pollutant generation rate is somewhat unpredictable, otherwise ventilation rates could simply be programmed to vary over time; and (d) energy costs are high due to severe climates, high energy prices, or large flow rates of outside air.

Recently with the development of less expensive and higher performance pollutant sensors, SBDCV is becoming increasingly attractive. The investment required to install SBDCV depends on the existing ventilation type. In buildings that already have variable air volume ventilation with digital controls, $\mathrm{CO}_{2}$-based ventilation control requires little additional investment (typically a few thousand dollars) per zone controlled. If extensive installation of flow-control hardware and control equipment is required to implement SBDCV, the required investment will be much larger.

\subsection{Use of $\mathrm{CO}_{2}$ sensors for demand-controlled ventilation}

At present, most SBDCV systems are based on monitoring of $\mathrm{CO}_{2}$ concentrations. $\mathrm{CO}_{2}$ sensors provide a relatively inexpensive way to indirectly monitor the indoor air quality component related to bioeffluents. The emission rates of some other indoor pollutants may also be correlated roughly with $\mathrm{CO}_{2}$ emission rates. For example, VOC and particle emissions from office equipment (used by occupants) may vary approximately with occupancy. On the other hand, the rate of VOC emissions from building materials and furnishings is likely to correlate poorly with occupancy.

Users of $\mathrm{CO}_{2}$-based SBDCV systems are often attempting to automatically control the rate of minimum outside air supply per occupant. Current standards and codes for minimum ventilation rates in large buildings, such as ASHRAE Standard 62-1989 'Ventilation for Acceptable IAQ' [2], list minimum rates of outside air supply per occupant. The presumption within these standards is that the specified minimum rate of ventilation per occupant is adequate for the control of both occupant-generated pollutants and other indoor-generated pollutants. Because pollutant emission rates from sources other than occupants vary greatly among buildings, this presumption can lead to IAQ problems. A proposed revision to ASHRAE Standard 62 [13] specified minimum ventilation rates that are the sum of minimum ventilation rates per occupant and minimum ventilation rates per unit floor area.

In buildings with a high occupant density, it is more likely that the prescribed minimum rates of outside air supply per occupant also result in acceptable concentrations of pollutants not generated by occupants. For this reason, the use of $\mathrm{CO}_{2}$ sensors to control outside air is particularly attractive in buildings or rooms with a high occupant density, e.g., auditoriums and meeting rooms.

As illustrated in Fig. 1, there is a direct relation between ventilation rates per person and steady-state indoor $\mathrm{CO}_{2}$ concentrations. Based on the relationship illustrated in Fig. 1, a control system that provides just enough outside air to maintain $\mathrm{CO}_{2}$ concentrations below $1000 \mathrm{ppm}$ or $800 \mathrm{ppm}$ may be considered.' Such a control scheme is likely to be too simple for many buildings. For example, in an office building with a low occupant density and occupancy only during the daytime, a few hours could elapse after the start of occupancy before indoor $\mathrm{CO}_{2}$ concentrations reach $1000 \mathrm{ppm}$. If no outside air ventilation was provided during this period, indoor concentrations of pollutants that are not generated by occupants could be excessive, leading to occupant complaints and health risks. To devise a control scheme for SBDCV based on indoor $\mathrm{CO}_{2}$ sensors, the dynamic nature of the relationship between occupancy, outside air supply, and $\mathrm{CO}_{2}$ concentrations must be considered. Also, a judgment is required regarding the adequacy of the ventilation control scheme for indoor pollutants generated from sources other than occupants. Additional types of pollutant sensors may be necessary to assure adequate IAQ.

There are a number of potential control strategies for using $\mathrm{CO}_{2}$ sensors and a variety of possible locations for sensing the $\mathrm{CO}_{2}$ concentration. Most studies have placed the sensor in the return air duct. The control approach described above, with no outside air supply (or only a small amount of outside air supply) before the $\mathrm{CO}_{2}$ concentration reaches a setpoint has received the most attention. In applications or modeling studies, this approach is sometimes combined with an earlymorning purge of the building to dilute pollutants that accumulated during the night $[14,15]$. One other control strategy that has been recently proposed $[16,17]$ is modulation of the rate of outside air supply so that it is proportional to the indoor rate of $\mathrm{CO}_{2}$ generation, determined from $\mathrm{CO}_{2}$ measurements and mass balance calculations. This strategy is attractive because the indoor $\mathrm{CO}_{2}$ generation rate is a much better surrogate for occupancy than the indoor $\mathrm{CO}_{2}$ concentration.

Although a SBDCV system, with only $\mathrm{CO}_{2}$ sensors, is clearly imperfect because it does not react to pollutants other than $\mathrm{CO}_{2}$, most existing ventilation systems have no system for measuring or automatically controlling the minimum rate of outside air supply. An imperfect SBDCV system based

\footnotetext{
${ }^{1}$ The SBDCV system will typically regulate the minimum outside air supply. Economizer controls may increase outside air quantities during periods of mild weather.
} 
solely on $\mathrm{CO}_{2}$ sensors may still be superior to the current practice which can lead to both excessive and inadequate rates of minimum outside air supply.

\subsection{Use of $\mathrm{VOC}$ and $\mathrm{CO}_{2}$ sensors}

$\mathrm{CO}_{2}$ sensors do not respond to indoor pollutant emissions that are unrelated to occupancy such as the emissions from building materials and furnishings. Thus, in buildings where the human pollutant load is not dominant, $\mathrm{CO}_{2}$-based SBDCV could lead to insufficient ventilation. Consequently, there is an interest in the use other gas pollutant sensors, primarily VOC sensors, often in conjunction with $\mathrm{CO}_{2}$ sensors. The cost of VOC sensors is decreasing and the performance, e.g., sensitivity and stability, is improving; however, existing VOC sensors may still have an inadequate sensitivity and stability. Additionally, the appropriate use of VOC sensors is complicated because there is a high variability in the potency of different VOCs to cause health effects and because maximum acceptable VOC concentrations, for mixtures of VOCs, have not been established.

There is evidence that TVOC concentrations exceeding a few milligrams per cubic meter are likely to lead to health symptoms [6-8]; however, lower concentrations are not necessarily acceptable. One of the initial opportunities for use of VOC sensors in SBDCV is to ensure that VOC concentrations do not exceed some relatively high level. This type of control system might reduce complaints during periods of temporary high indoor VOC emission rates, such as the high emission rates associated with painting or installation of carpeting.

\subsection{Use of other types of sensors for $S B D C V$}

In residential buildings relative humidity sensors have been used for ventilation control, but they only are effective for moisture control. Other residential pollutants are not wellcorrelated with humidity.

In buildings with variable occupancy schedule, but where the number of occupants during the period of occupancy is relatively stable (e.g., some classrooms), occupancy sensors may provide the most cost-effective solution for SBDCV. The occupancy sensor would increase ventilation from a low value to a fixed higher value during periods of occupancy.

Particle sensors might be used to control ventilation rates in buildings or rooms (e.g., smoking lounges) with high particle generation rates. Unfortunately, most high quality real-time particle sensors cost several thousand dollars. One manufacturer [18] markets a solid state sensor that responds to gaseous components of cigarette smoke and the manufacturer provides some information on the response of the detector in environments with smoking. Faulkner et al. [19] used a low cost (US\$2500) optical particle counter in a system that automatically modulated air recirculation rates (thus air filtration rates) in a clcan room, but this instrument is too expensive for use in most normal indoor environments. The cost of instruments that use light scattering to measure particle concentrations in real time is decreasing, thus, cost-effective particle sensors may be available in the future.

\subsection{Potential influence of SBDCV on energy use}

One of the major driving forces for SBDCV is the fact that higher outside-air ventilation rates can increase building energy use, the required HVAC equipment capacities, and the associated energy and equipment costs. Computer models have been used to examine the relationships between outside air ventilation rates and energy use [20-25]. The findings vary with the type of building, type of HVAC system, occupant density, and climate. For example, if minimum ventilation rates are reduced from $10 \mathrm{l} \mathrm{s}^{-1}(20 \mathrm{cfm})$ per occupant to $51 \mathrm{~s}^{-1}(10 \mathrm{cfm})$ per occupant, the estimated savings in HVAC energy (i.e., fan, heating and cooling energy) vary from negligible to approximately $50 \%$. In office buildings with HVAC systems that have an economizer, increasing or decreasing the minimum ventilation rates from approximately $101 \mathrm{~s}^{-1}(20 \mathrm{cfm})$ per occupant to $2.51 \mathrm{~s}^{-1}(5 \mathrm{cfm})$ per occupant is likely to change total HVAC energy use by only a few percent to $10 \%[20,21,24,25]$. The larger energy savings are expected in buildings with a high and variable occupant density (e.g., sports arenas, auditoriums, courtrooms, theaters, etc.) located in a severe climate.

The potential energy savings cited above are model predictions for large buildings that supply a mixture of outside and recirculated air. In buildings that supply $100 \%$ outside air to the conditioned space, larger savings would be expected. In these buildings, fan energy savings will be especially significant because fan power increases approximately with the cube of the flow rate. Thus a modest decrease of $20 \%$ in the air flow translates into $50 \%$ fan energy savings. However, in buildings that supply a mixture of outside and recirculated air, SBDCV will have only a small influence of supply flow rates and fan energy.

Presently, the rates of outside air supply to most large buildings is rarely measured and poorly controlled. The limited available data suggests that many U.S office buildings have minimum ventilation rates substantially above or below the rates specified in ventilation codes (e.g., Refs. [26-29]). The practice of setting minimum rates at a level necessary for the highest anticipated occupancy will often lead to ventilation rates above the levels specified in codes. SBDCV offers the potential to save energy in over-ventilated buildings and to improve IAQ (with some increase in energy use) in under-ventilated buildings.

\subsection{Real-time control of electricity demand combined with $S B D C V$}

To reduce use of electricity when electricity costs are highest, SBDCV systems may be used in conjunction with the energy management systems (EMS) that are increasingly common in medium-size and large commercial buildings. EMS use a network of sensors to obtain real time data on the 
Table 1

Suggested characteristics for pollutant sensors used for SBDCV

\begin{tabular}{|c|c|c|c|c|c|c|}
\hline Pollutant & Typical range indoors & $\begin{array}{l}\text { Sensor } \\
\text { minimum } \\
\text { detection limit }\end{array}$ & $\begin{array}{l}\text { Sensor } \\
\text { resolution }\end{array}$ & $\begin{array}{l}\text { Sensor } \\
\text { maximum drift } \\
\text { between } \\
\text { calibrations }\end{array}$ & Sensor required specificity & $\begin{array}{l}\text { Maximum period } \\
\text { hetween } \\
\text { measurements }\end{array}$ \\
\hline Carbon dioxide & $\begin{array}{l}350-2000 \mathrm{ppm} \text { (often } \\
<1000 \mathrm{ppm} \\
\text { maximum) }\end{array}$ & $350 \mathrm{ppm}$ & $\leq 50 \mathrm{ppm}$ & $50 \mathrm{ppm}$ & $\begin{array}{l}\text { insensitive to temperature, } \\
\mathrm{RH} \text {, other gases }\end{array}$ & $30 \mathrm{~min}$ \\
\hline Humidity & $\begin{array}{l}10 \%-80 \% \text { RH } 0.002- \\
0.015 \text { absolute } \\
\text { humidity }\end{array}$ & $10 \% \mathrm{RH}$ & $\leq 5 \% \mathrm{RH}$ & $5 \% \mathrm{RH}$ & $\begin{array}{l}\text { insensitive to temperature, } \\
\text { other gases }\end{array}$ & $30 \mathrm{~min}$ \\
\hline $\begin{array}{l}\text { Particles in indoor } \\
\text { spaces with } \\
\text { minimal smoking }\end{array}$ & $\begin{array}{l}10-100 \mu \mathrm{g} \mathrm{m}^{-3} \\
\text { (minimal smoking) }\end{array}$ & $10 \mu \mathrm{g} \mathrm{m}^{-3}$ & $\leq 0.05 \mu \mathrm{g} \mathrm{m}^{-3}$ & $0.05 \mu \mathrm{g} \mathrm{m}^{-3}$ & $\begin{array}{l}\text { insensitive to temperature, } \\
\text { gases }\end{array}$ & 30 min \\
\hline $\begin{array}{l}\text { Particles in smoking } \\
\text { rooms }\end{array}$ & unknown & $50 \mu \mathrm{g} \mathrm{m}^{-3}$ & $\leq 10 \mu \mathrm{g} \mathrm{m}^{-3}$ & $10 \mu \mathrm{g} \mathrm{m}^{-3}$ & $\begin{array}{l}\text { insensitive to temperature, } \\
\text { gases }\end{array}$ & $10 \mathrm{~min}$ \\
\hline $\begin{array}{l}\text { TVOC high linit } \\
\text { control only }\end{array}$ & $0.1-5 \mathrm{mg} \mathrm{min}^{-3}$ & $1 \mathrm{mg} \mathrm{m}^{-3}$ & $50.2 \mathrm{mg} \mathrm{III}^{-3}$ & $0.2 \mathrm{mg} \mathrm{m}^{-3}$ & $\begin{array}{l}\text { responds to total carbon for } \\
\text { VOCs with } 50^{\circ} \mathrm{C}-250^{\circ} \mathrm{C} \\
\text { boiling point }\end{array}$ & $30 \mathrm{~min}$ \\
\hline $\begin{array}{l}\text { TVOC routine } \\
\text { control }\end{array}$ & $\begin{array}{l}0.1-5 \mathrm{mg} \mathrm{m}^{-3}, \text { usually } \\
<1 \mathrm{mg} \mathrm{m}^{-3}\end{array}$ & $0.04 \mathrm{mg} \mathrm{m}^{-3}$ & $0.04 \mathrm{mg} \mathrm{m}^{-3}$ & $0.04 \mathrm{mg} \mathrm{m}^{-3}$ & $\begin{array}{l}\text { responds to total carbon for } \\
\text { voCs with } 50^{\circ} \mathrm{C}-250^{\circ} \mathrm{C} \\
\text { boiling point }\end{array}$ & $30 \min$ \\
\hline
\end{tabular}

building operating and environmental conditions. Some large electricity consumers are connected with the utility through a phone line, in order to receive requests for reducing the peak electricity load, as well as to communicate present and forecasted demand. The building operator traditionally closes the link, instructing the EMS to respond to the utility signals. However, this current manual load shedding/shifting response to utility prices is too labor intensive and operationally inefficient for large-scale implementation.

Energy management systems which can control loads in an automatic manner in response to real-time prices have been developed [30]. Real-time prices are sent to the customer whose EMS can modulate some of the loads (e.g., air conditioning, ventilation, non-essential lighting), in order to reduce peak demand, maintaining all the essential services. SBDCV systems coupled with EMS could be used to modulate the ventilation load by controlling the tempcrature, VOCs, and carbon dioxide levels within a window of acceptance, whose limits may be adjusted as a function of the realtime prices. In theory, this strategy can save energy and substantially decrease peak. Large commercial buildings with long thermal time constants, low pollutant emission from the building materials, building furnishings and consumer products, as well as with a large volume of air per occupant, are the most attractive buildings for this type of ventilation control.

\section{Criteria for sensors used for SBDCV}

The need to control and automate industrial processes has led to the appearance in the market of a wide array of sensors. These sensors allow the monitoring and control of a large number of parameters, at a generally modest price. The sensor technologies for indoor air pollutants at present lag in terms of performance-to-price ratio relative to many industrial sensors. This lag may be due to the lack of a strong market pull for the development of mass-produced low-cost indoor air quality sensors. Additionally, environmental sensors for industrial applications are normally designed to deal with higher, easier to measure, pollutant concentrations than those present in non-industrial buildings. A review of existing and emerging sensor technologies for SBDCV is provided in our report [12].

Table 1 lists suggested characteristics of pollutant sensors used for SBDCV in non-industrial buildings. To construct this table, we assumed that the sensors' minimum detection limits should approximately correspond to the lower limit of pollutant concentrations inside buildings and that the sensor resolution and maximum drift between calibrations should be less than approximately $10 \%$ of a typical indoor pollutant concentration. For all sensors, we have assumed that measurements should be available at least every $30 \mathrm{~min}$ which is on the order of a typical ventilation time constant. For particle sensors used in smoking rooms, a faster sensor response is suggested. The suggested criteria in Table 1 are based substantially on professional judgments and are intended only as approximate criteria.

Suggested criteria for particle sensors are expressed in terms of particle mass per unit volume of air, consistent with the health based standards for particles. When particle sensors measure particle number concentration as a function of particle size, a conversion to mass concentration is necessary using a typical particle density. Different performance criteria are suggested for control of ventilation in general indoor spaces, where particle concentrations are usually much less 
that $100 \mu \mathrm{g} \mathrm{m}^{-3}$ and for control of ventilation in smoking rooms which may have higher concentrations. For spaces with minimal smoking, we assumed that the goal would be to generally maintain particle concentrations well below the concentration specified in the national ambient air quality standard of $75 \mu \mathrm{g} \mathrm{m}^{-3}$ for particles with a diameter less than $10 \mu \mathrm{m}$. For smoking rooms, and other spaces such as bars with high levels of smoking, the control system would likely be designed to maintain particle concentrations below a higher setpoint, roughly comparable to the value in the national ambient air quality standard of $75 \mu \mathrm{g} \mathrm{m}^{-3}$.

For TVOC sensors, we also provide criteria for two applications. The first application is the use of TVOC sensors only to prevent unusually high indoor TVOC concentrations (e.g., $>1 \mathrm{mg} \mathrm{m}^{-3}$ ) during periods of unusually high indoor VOC emission rate. Although the relationship between TVOC concentration and health effects are poorly understood, these unusually high TVOC concentrations are more likely to be a cause of adverse health effects. The second application is the use of TVOC sensors, possibly in combination with $\mathrm{CO}_{2}$ sensors, for routine control of ventilation rates. In this application, the sensor must be suitable for the lower TVOC concentrations that typically occur indoors. Because the potential of different VOCs to cause irritation varies widely, the TVOC concentration may be a poor parameter for routine control of ventilation rate.

Table 1 suggests a maximum value of sensor drift between calibrations. The frequency at which building operators would be willing to calibrate sensors is unknown; however, we doubt that sensors would be calibrated more than once or twice a year in most buildings.

\section{Case studies of SBDCV}

\subsection{Limitations of existing literature and literature reviewed}

There is a lack of well-documented case studies describing in detail the IAQ performance, the energy savings, and the cost-effectiveness of SBDCV. Most of the literature reviewed provides incomplete information on savings and cost effectiveness and is based on short-term studies. The literature involves case studies of a few days to a couple of years. No really long-term case studies (e.g., 10 years) are reported. Only a few studies included assessments of occupants' ratings.

Most of the case studies used $\mathrm{CO}_{2}$ or humidity sensors to control the ventilation rate, thus, the literature provides very limited information on the use of other sensors. The case studies with $\mathrm{CO}_{2}$-based SBDCV generally did not include measurements of a broad range of pollutants. An exception is a comprehensive case study $[31,32]$ that included measurements of formaldehyde and VOC concentrations. Thus, there are insufficient data to determine if $\mathrm{CO}_{2}$ controls cause problems with other pollutants, although modeling studies predict that elevated concentration of other pollutants are likely without proper precautions [15,33]. (In a couple of case studies it was concluded that $\mathrm{CO}_{2}$ control is not adequate when there is tobacco smoking, )

Developing general conclusions about the magnitude of energy savings from SBDCV is difficult because the energy savings can vary greatly depending on the climate, type of ventilation system, occupancy pattern, use of heat recovery, pollutant setpoint, and on the reference case used as the baseline for estimates of savings. Despite these limitations, the literature provides an indication of the likely range of energy savings and associated payback periods for certain types of buildings.

The sources of literature reviewed are the following: (1) A state-of-the-art review of demand-controlled ventilation carried out by the International Energy Agency [34] reviewed 31 papers published between 1979 and 1989. Only 12 papers contained quantitative information on the energy savings achieved or payback time achieved. (2) A subsequent report from the International Energy Agency [35] contained 13 papers on case studies of demand controlled ventilation implemented in different IEA Countries (seven studies related to dwellings). Again energy savings and costeffectiveness are not always described in detail. (3) Nine additional recent papers on case studies were reviewed. These papers describe case studies in three auditoriums [36-38], one office building $[31,32]$, one university restaurant $[40]$, one sports arena [41], and one dwelling [42]. Two of the papers related to auditoriums describe case studies already partially described in the IEA review [35]. (4) Six papers $[14-17,33,39]$ that describe computer modeling to evaluate $\mathrm{CO}_{2}$-based demand-controlled ventilation were also reviewed.

\subsection{Findings from case studies of $S B D C V$}

\subsubsection{Assembly rooms}

The case studies related to assembly rooms (e.g., auditoriums, lecture halls, concert halls, social clubs, cinemas and theaters, indoor sports arenas) reported substantial HVAC energy savings from $11 \%$ (cinema) to over $50 \%$ (auditoriums). Payback times are in the range 1-3 years, with the exception of the cinema case study which reported a 4.8-year payback period.

The cost-effectiveness of SBDCV in this type of building is associated with the highly variable and unpredictable occupancy pattern. Human occupancy is also the main source of pollutants in these building types because of the high occupant density. For example the indoor sports arena can have an occupancy ranging from a few hundred to 18,000 [41]. One added bonus of SBDCV, noted in the sports arena case study, is lower maintenance costs due to longer filter life. This type of benefit should also be realized in other types of buildings with SBDCV.

$\mathrm{CO}_{2}$ sensors were used to control the ventilation rate in seven of the investigations. Two case studies used an IAQ 
mixed gas sensor. The performance of the sensors was generally described as satisfactory. In a few studies, $\mathrm{CO}_{2}$ sensors were used for control of ventilation, and mixed gas (VOCs) sensors were simultaneously used to collect data on VOC concentrations [34].

Fig. 4 shows an example of computer predictions of energy savings from $\mathrm{CO}_{2}$-based SBDCV in an auditorium [43] located in a cold climate (Norway). The reference case for the energy savings calculations was continuous ventilation at a rate sufficient to maintain $\mathrm{CO}_{2}$ below a set point with full occupancy of the auditorium. As expected, the predicted energy savings increase as the occupancy decreases below full occupancy. As maximum allowable concentration of $\mathrm{CO}_{2}$ increases, energy savings decrease.

Fig. 5 shows a strong correlation between $\mathrm{CO}_{2}$ and VOC concentrations from a study in a lecture hall [34]. Due to the high occupant density, the occupants may have been the dominant source of VOCs as well as the dominant source of $\mathrm{CO}_{2}$.

\subsubsection{Office buildings}

Three of the case studies of office buildings [35] involved only conference or board rooms (10-20 persons) within office buildings. $\mathrm{CO}_{2}$ ventilation control reportedly gave good results in these experiments, but may not be cost-effective due to the small amount of energy used to ventilate small conference rooms.

Only a few experimental studies of SBDCV applied to the primary office areas of large office buildings are reported in the literature [31,32,34]. All of the studies reportcd significant energy savings. For example, in a study within a Finish office [34], heating energy was reduced $10 \%$ to $40 \%$. In each study, the SBDCV performed satisfactorily without causing an increase in occupant complaints. A comprehensive longterm experimental study $[31,32]$ compared energy use, air pollutant concentrations, and occupant satisfaction with air quality on two nearly identical floors of an office building, with $\mathrm{CO}_{2}$-control of ventilation implemented on one floor. The $\mathrm{CO}_{2}$-based control system saved energy and appeared to

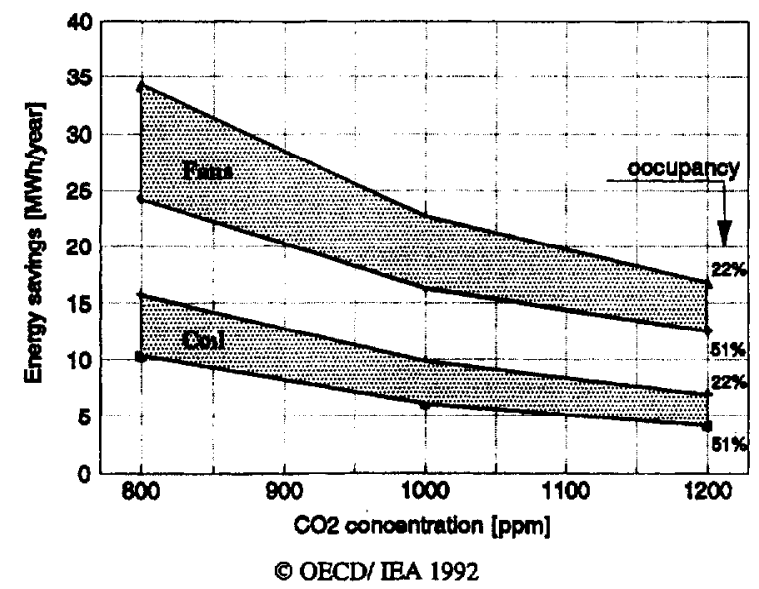

Fig. 4. Energy saving in an auditorium (University of Trondheim, Norway) as a function of the allowable $\mathrm{CO}_{2}$ concentration (from Ref. [43], reproduced with permission).

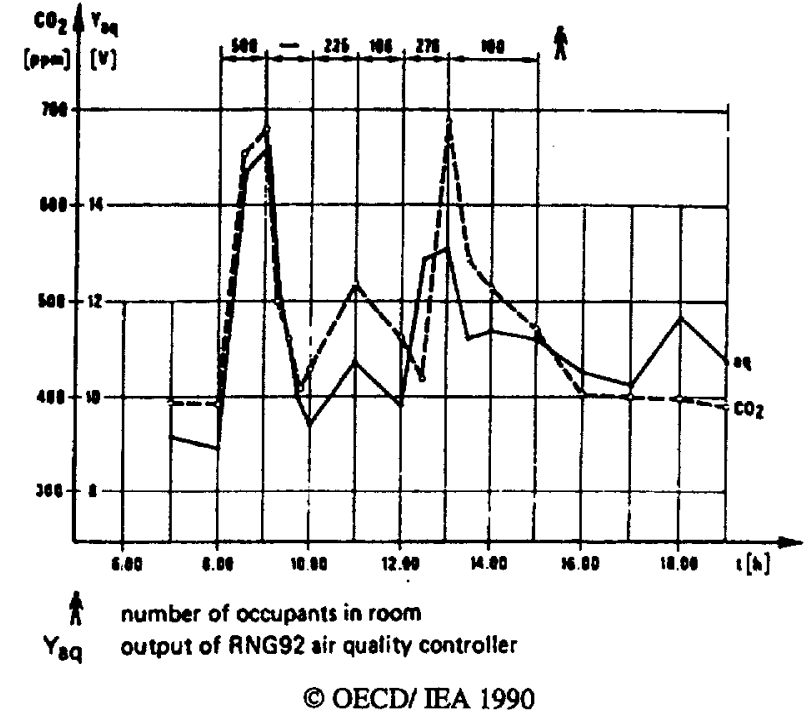

Fig. 5. Comparative measurements with a $\mathrm{CO}_{2}$ sensor and a mixed gas sensor (VOCs) in a lecture hall of Trondheim University, Norway (from Ref. [34], paper 87/e, reproduced with permission).

reduce average and peak VOC concentrations. Formaldehyde concentrations and occupant perceptions of indoor air quality were similar on the two floors.

Six papers used computer simulations to evaluatc with $\mathrm{CO}_{2}$-control of ventilation in office buildings $[14-17,33,39]$. Meckler [39] simulated a large 10-story office building in five different locations (Miami, Atlanta, Washington DC, New York, and Chicago). The simulation results indicate significant heating (gas) savings and modest electricity savings. The predicted payback times for the five cities are in the range 1.4-2.2 years. In other simulations, predicted reductions in heating plus cooling coil energy for an office building in Madison, Wisconsin and Miami, Florida ranged from approximately $5 \%$ to $50 \%$ depending on the HVAC system type, occupancy, the assumed indoor airflow pattern, and the control strategy $[14,15]$.

Carpenter [33] performed one of the most comprehensive simulation-based studies of $\mathrm{CO}_{2}$-based $\mathrm{SBDCV}$ in office buildings. His simulations involved several climates and HVAC system types (single-zone roof-top systems, central multizone dual-duct systems, and central VAV systems) and different outside air control strategies. Energy performance and indoor $\mathrm{CO}_{2}$ and formaldehyde concentrations were predicted. For the Chicago climate (results are reportedly similar in other climates), this simulation study indicates that savings in cooling energy are negligible to a few percent while savings in heating energy are about $5 \%$ to $30 \%$. Cooling energy savings are less than initially expected because the SBDCV system tends to provide higher quantities of outside air in the afternoons when outdoor temperatures are higher. The predictions of indoor formaldehyde concentrations in this study are likely to be unrealistic, since the formaldehyde source strength was considered constant. However, the predicted differences between formaldehyde concentrations with and without $\mathrm{CO}_{2}$ control should indicate the expected impact of 
this type of ventilation control system on concentrations of other indoor-generated pollutants that have a relatively constant emission rate. Predicted indoor formaldehyde concentrations during occupancy were higher by a factor of 1.5 to 3 when the $\mathrm{CO}_{2}$ control system was used. The higher timeaverage formaldehyde concentrations during occupancy were a consequence of the high concentrations in the mornings before $\mathrm{CO}_{2}$ concentrations exceeded the control-system setpoint and the supply of outside air was started. These predictions and similar predictions [15] illustrate that provision of no outside air until $\mathrm{CO}_{2}$ levels reach a set point could cause IAQ problems. A morning purge cycle with outside air has been explored as an option to prevent these problems $[15,33]$.

\subsubsection{Bank}

In the bank building subject to $\mathrm{CO}_{2}$ ventilation control [34], the estimated reduction in total HVAC energy consumption was $8 \%$, resulting in an estimated payback time of $2-3$ years.

\subsubsection{University restaurant}

One large university restaurant (550 persons capacity) with $\mathrm{CO}_{2}$ ventilation control showed significant energy savings with an estimated payback of only a few months [40]. The reference was conventional time-clock control with ventilation provided $12 \mathrm{~h}$ per day at a rate sufficient for full occupancy. In the restaurant area there is smoking and cooking activities. For $\mathrm{CO}_{2}$ concentrations above about $750 \mathrm{ppm}$, a good correlation was found between the outputs of the $\mathrm{CO}_{2}$ and mixed gas sensors [40].

\subsubsection{Schools}

Two studies of schools subject to the application SBDCV were reviewed. In a Swedish study [35], infra-red occupancy sensors were used to provide the control signal for adjustments of supply air dampers that increased or decreased the ventilation rate. The application of SBDCV reduced ventilation energy requirements by approximately $50 \%$ with a payback time of approximately 4.5 years.

In one of the first investigations of SBDCV [34], computer simulations were used to evaluate SBDCV in typical U.S. school buildings. The simulations resulted in estimated payback periods of 3 to 4 years.

\subsubsection{University library}

The application of $\mathrm{CO}_{2}$-based SBDCV in a university library [34] produced modest results. There were significant differences in IAQ in different parts of the building leading the investigators to recommend that $\mathrm{CO}_{2}$ analyzers be installed on each floor. Based on simulations, the estimated payback time was 6.3 years. A library has a variable pollutant load associated with occupancy, but the pollutant load associated with library materials (books, photocopiers) may be dominant. This study did not determine if $\mathrm{CO}_{2}$ control resulted in acceptable concentrations of other pollutants.

\subsubsection{Dwellings}

Ten case studies of SBDCV in dwellings were examined [34,35,42]. All but one study was performed in Europe. Some of these case studies involved multiple dwellings. Most of the case studies ( 8 out of 10 ) used only relative humidity (RH) sensors for ventilation control due to their low cost. In general the performance of these sensors was reported as satisfactory in terms of avoiding condensation and mold growth, although these studies did not clearly show that condensation and mold problem would have occurred in the absence of SBDCV. The reported energy savings range from $0 \%$ to $60 \%$. One study reporting a modest increase in energy use [42]. This very wide range reflects different types of dwellings, ventilation types, and climates. The use of ventilation with heat recovery significantly reduced the savings. The reported cost-effectiveness of these systems was poor. Even in the case study where 50-60\% energy savings were estimated, the estimated payback was 5-6 years. In dwellings, $\mathrm{RH}$ is poorly correlated with occupancy, thus, controlling ventilation based on RH will not necessarily result in increased ventilation when occupants are present.

\section{Conclusions}

SBDCV appears to be an increasingly attractive technology option for controlling indoor air quality while minimizing energy use and costs. Based on the review of literature and theoretical considerations, the application of SBDCV is more cost-effective in applications with the following characteristics: (1) A single or small number of pollutants dominate, so that ventilation sufficient to control the concentration of the dominant pollutants provides effective control of all other pollutants. (2) The occupancy schedule and occupancy level, or the activities carried out by occupants which generate pollutants, are variable and unpredictable. (3) Space heating and cooling requirements are high due to a severe climate or expensive energy.

There is a limited number of well-documented case studies that quantify the energy savings and the cost-effectiveness of SBDCV. The case studies reviewed suggest that in appropriate applications, SBDCV produces significant savings with a payback period typically of a few years. The literature suggests that a large number of office buildings with a variable and unpredictable occupancy may benefit from the application of SBDCV. Additionally, SBDCV can also be used to improve the current practice of the control of outside-air ventilation in office buildings, by providing a feedback loop to monitor and control occupant-generated bioefflucnts.

The cost-effectiveness of each application of SBDCV needs to be assessed as the energy savings are a function of the occupancy level and schedule (including occupant activities), climatic conditions, HVAC type, building type and size, pollutant generation rates, and the cost of the control system. To decide about the application of SBDCV in a build- 
ing, a simulation is recommended to estimate the energy savings and the corresponding cost-effectiveness.

The application of SBDCV in dwellings with mechanical ventilation can provide some energy savings, but this application will often not be cost-effective due to the high cost of SBDCV controls and the modest air flow rates in dwellings.

The high price and inadequate performance of many IAQ sensors is a key constraint to the widespread application of SBDCV.

\section{Acknowledgements}

This work was supported by the Assistant Secretary of Energy Efficiency and Renewable Energy, Office of Building Technology, State, and Community Programs, Office of Building Systems of the U.S. Department of Energy (DOE) under contract No. DE-AC03-76SF00098 and by the NATO Scientific Affairs Division.

\section{References}

[1] A. Persily, W.S. Dols, The relation of $\mathrm{CO}_{2}$ concentration to office building ventilation, ASTM Standard Technical Publication 10671990, American Society for Testing and Matcrials, Philadelphia, 1990, pp. 77-91

[2] ASHRAE, Standard 62-1989, Ventilation for acceptable indoor air quality, American Society of Heating, Refrigerating and Air-Conditioning Engineers, Atlanta, 1989.

[3] ASIIRAE, Physiological principles and comfort, in: ASHRAE Handbook, Fundamentals, Chap. 8, American Society of Heating, Refrigerating and Air-Conditioning Engineers, Atlanta, 1993.

[4] A. Baughman, E. Arens, Indoor humidity and human health: Part 1. Literature review of health effects of humidity-influenced indoor pollutants, ASHRAE Transactions 102 (1) (1996) 193-211.

[5] E. Arens, A. Baughman, Indoor humidity and human health: Part 2. Buildings and their systems, ASHRAE Transactions 102 (1) (1996) 212-221.

[6] L. Molhave, B. Bach, O.F. Pedersen, Human reactions to low concentrations of volatile organic compounds, Environ. Int. 12 (1986) 167175.

[7] L. Molhave, Z. Lui, A.H. Jorgensen, O.F. Pedersen, S.K. Kjaergaard, Sensory and physiological effects on humans of combined exposures to air temperatures and volatile organic compounds, Indoor Air 3 (3) (1993) 155-169.

[8] J. TenBrinke, S. Selvin, A.T. Hodgson, W.J. Fisk, M.J. Mendell, C.P. Koshland, J.M. Daisey, Develnpment nf new VOC exposure metrics and their relationship to sick building syndrome symptoms, submitted to Indoor Air, 1998.

[9] U.S. Environmental Protection Agency, Dosimetry of inhaled particles in the respiratory tract, Chap. 10, in: Air Quality Criteria for Particulate Matter, Vol. II of 3 vols., EPA/600/P-95/001bF, 1996.

[10] W.W. Nazaroff, A.J. Gadgil, C.J. Weschler, Critique of the use of deposition velocity in modeling indoor air quality, in: American Society of Testing and Materials Standard Technical Publication 1205, ASTM, Philadelphia, 1993.

[11] W.J. Fisk, R.K. Spencer, D.T. Grimsrud, F.J. Offermann, B. Pedersen, R. Sextro, Indoor Air Quality Control Techniques: Radon, Formaldehyde, Combustion Products. Noyes Data, Park Ridge, NJ, 1987.

[12] A.T. De Almeida, W.J. Fisk, Sensor-based demand controlled ventilation, LBNL-40599, Lawrence Berkeley National Laboratory, Berkeley, CA, 1997.
[13] ASHRAE, BSR/ASHRAE Standard 62-1989R, Ventilation for acceptable indoor air quality, public review draft, American Society of Heating, Refrigerating and Air-Conditioning Engineers, Atlanta, 1996.

[14] P.D. Knoespel, J.W. Mitchell, W.A. Beckman, Macroscopic model of indoor air quality and automatic control of ventilation airflow, ASHRAE Transactions 97 (2) (1991) 1020-1030.

[15] S.J. Emmerich, J.W. Mitchell, W.A. Beckman, Demand-controlled ventilation in a multi-zone office building, Indoor Environ. 3 (1994) 331-340.

[16] C.C. Federspiel, On-demand ventilation control: a new approach to demand-controlled ventilation, Proceedings of Indoor Air '96, Vol. 3, SEEC Ishibashi, Japan, 1996, pp. 935-940.

[17] Y.-P. Ke, S.A. Mumma, Using carbon dioxide measurements to determine occupancy for ventilation controls, Preprint BN-97-1-1 presented at the 1997 ASHRAE Annual Meeting, Boston, ASHRAE Transactions 103 (2) (1997) 365-374.

[18] Figaro, Air quality sensor, technical reference for TGS 800 , AMS 800 and Figaro 6604, Figaro USA, Wilmette, IL, 1994.

[19] D. Faulkner, W.J. Fisk, J.T. Walton, Energy savings in cleanrooms from demand-controlled filtration, J. Inst. Environ. Sci. 39 (2) (1996) 21-27.

[20] J. Eto, C. Meyer, The HVAC costs of increased fresh air ventilation rates in office buildings, ASHRAE Transactions 94 (2) (1988) 331340.

[21] J. Eto, The IIVAC costs of increased fresh air ventilation rates in office buildings, part 2, Proceedings of the Fifth International Conference on Indoor Air Quality and Climate, Vol. 4, International Conference on IAQ and Climate, Ottawa, 1990, pp. 53-58.

[22] T. Steele, M. Brown, ASHRAE standard 62-1989: energy, cost, and program implications, DOE/BP-1657, Bonneville Power Administration, Portland, OR, 1990.

[23] J.A. Ventresca, Operations and maintenance for indoor air quality: implications from energy simulations of increased ventilation, Proceedings of IAQ '91. ASHRAE. Atlanta, 1991, pp. 375-378.

[24] D.H. Mudarri, J.D. Hall, Increasing outdoor air flow rates in existing buildings, Proceedings of Indoor Air '93, Vol. 5, Indoor Air '93, Helsinki, 1993, pp. 21-26.

[25] D.H. Mudarri, J.D. Hall, Energy cost and IAQ performance of ventilation systems and controls, Proceedings of IAQ '96, ASHRAE, Atlanta, 1996, pp. 151-160.

[26] W.I. Fisk, D. Faulkner, R.J. Prill, Air exchange effectiveness of conventional and task ventilation for offices, published by ASHRAE in the Post-Conference Proceedings of IAQ ' 91 Healthy Buildings, September 4-8, Washington, DC, 1991, pp. 30-34.

[27] A.K. Persily, R.A. Grot, Ventilation measurements in large office buildings, ASHRAE Transactions 91 (2a) (1985) 488-502.

[28] B.H. Turk, et al., Indoor Air Quality and Ventilation Measurements in 38 Pacific Northwest Commercial Buildings, Vol. 1, Measurement Results and Interpretation, Lawrence Berkeley Laboratory, LBL22315 1/2, Berkeley, CA, 1987.

[29] R.A. Grot, P. Lagus, Air change rates in non-residential buildings in California, Prepared for the California Energy Commission by Lagus Applied Technology, 1995.

[30] J. Flood, Private communication, Utility Consulting Service, 8 Woodland Drive, Oak Ridge, NJ 07438, 1994, Tel.: + 1-201-697-0166.

[31] F. Haghighat, G. Donnini, IAQ and energy-management by demandcontrolled ventilation, Environ. Technol. 13 (1992) 351-359.

[32] F. Haghighat, R. Zmeureanu, G. Donnini, Energy savings in buildings by demand-controlled ventilation, Proceedings of Indoor Air '93, Vol. 5, Helsinki, 1993, pp. 51-56.

[33] S.E. Carpenter, Energy and IAQ impacts of $\mathrm{CO}_{2}$-based demand-controlled ventilation, ASHRAE Transactions 102 (2) (1996) 80-88. 
[34] International Energy Agency, in: W. Raatschen (Ed.), Demand-controlled ventilating systems: state of the art review, Published by the Swedish Council for Building Research, Stockholm, 1990.

[35] International Energy Agency, in: L.-G. Mansson (Ed.), Demandcontrolled ventilating systems: case studies, Swedish Council for Building Research, Stockholm, 1993.

[36] J. Fehlmann, H.-U. Wanner, M. Zamboni, Indoor air quality and energy consumption with demand-controlled ventilation in an auditorium, Proceedings of Indoor Air '93, Vol. 5, Indoor Air '93, Helsinki, 1993, pp. 45-50.

[37] S. Svennberg, Demand controlled ventilation in an auditorium in Tyreso, Proceedings of the 14th AIVC. Conference, Energy Impact of Ventilation and Air Infiltration, Published by the Air Infiltration and Ventilation Centre, Coventry, UK, 1993, pp. 1-18.

[38] M. Zamboni, O. Berchtold, Ch. Filleux, J. Fehlmann, F. Drangsholt,
Demand-controlled ventilation-an application to auditoria, Indoor Air 2 (1992) 263-271.

[39] M. Meckler, Demand-controlled ventilation strategies for acceptable LAQ, Heating, Piping, and Air Conditioning (May 1994) 71-74.

[40] S. Meier, Mixed gas or $\mathrm{CO}_{2}$ sensors as a reference variable for demand-controlled ventilation, Proceedings of Indoor Air '93, Vol. 5, Indoor Air '93, Helsinki, 1993, pp. 85-90.

[41] S. Smith, Thermal storage HVAC system retrofit provides economical air conditioning, ASHRAE Journal (March 1993) 28-30.

[42] J. Kesselring, et al., Evaluation of residential ventilation controller technology, Proceedings of Indoor Air '93, Vol. 5, Indoor Air '93, Helsinki, 1993, pp. 73-78.

[43] International Energy Agency, Demand controlled ventilation systemssource book, Energy Conservation in Buildings and Community Systems Programme, Swedish Council for Building Research, Stockholm, 1992. 